\title{
Critiquing Interviewing as a Data Collection Method
}

\author{
Costa Hofisi \\ North-West University, South Africa \\ costa.hofisi@nwu.ac.za \\ Miriam Hofisi \\ North-West University, South Africa \\ Stephen Mago
}

Great Zimbabwe University

\section{Doi:10.5901/mjss.2014.v5n16p60}

\begin{abstract}
Interviewing is one of the data collection methods which are employed when one adopts the qualitative methodology to conduct research. This article relies on extensive literature review to critique interviewing as a data collection method. Although interviews have various forms and styles, it is important to note that there is no one interview style that fits every occasion or all respondents. The interviewer must work diligently to ensure the validity and reliability of the interview data otherwise, interviewers themselves, can turn out to be weaknesses due to their own bias, subjectivities and lack of interviewing skills. It is also important to note that interviewers themselves become part of the "interviewing picture" by asking questions and responding to the respondent and sometimes even sharing their experiences with interviewees; working with the interview data, selecting from it, interpreting and describing and analysing it regardless of their discipline and dedication in keeping the interview data as the product of the respondent. Weaknesses of interviewing have been both discussed and critiqued from different theoretical perspectives which are "postmodern, feminist, sociolinguistic" "conversation analytic", "ethnomethodological perspectives" and even data analysis.
\end{abstract}

Keywords: Interview, semi-structured interview, unstructured interview, in-depth interview

\section{Introduction}

Researchers use a variety of techniques to conduct research. These techniques fall into two main categories which are quantitative and qualitative methodologies. Interviewing is one of the data collection methods which are employed when one adopts the qualitative methodology to conduct research (Byrne: undated). Babbie and Mouton (2011:289) define a qualitative interview as "an interaction between an interviewer and a respondent in which the interviewer has a general plan of inquiry but not a specific set of questions that must be asked in particular words and in a particular order". An interview can also be defined as a purposeful conversation (Berg: 1989, Dexter: 1970; Guba: 1985). Mishler (1986) on qualitative research interviews observes that:

\footnotetext{
At its heart, it is a process that an interview is a form of discourse. Its particular features reflect the distinctive structure and aims of interviewing, namely, that it is a discourse shaped and organized by asking and answering questions. An interview is a joint product of what interviewees and interviewers talk about together and how they talk with each other. The record of an interview that we researchers make and then use in our work of analysis and interpretation is a representation of that talk.
}

Therefore, it is important to note that an interview involves at least two people who are the interviewer and the interviewee. While the interviewer asks the questions the interviewee is there to respond to the questions asked by the interviewer. However, it is important to note that "there is no single interview style that fits every occasion or all respondents" (Denzin \& Lincoln siting Converse \& Schuman: 1974).

Moreover, Seidman (1998) writes that "Interviewing covers a wide range of practices" (including face-to-face, focus group interviews and telephonic interviews). There are "tightly structured, survey interviews with preset, standardised, 
normally closed questions (on) the other end of the continuum are open-ended, apparently structured, anthropological interviews" This continuum also includes semi-structured interviews. Babbie \& Mouton (2011) puts interviewing into three broad categories which are "basic individual interviewing", "depth individual interviewing" and "focus group interviews".

There are also two broad types of interviews which are standardised and non-standardised (Wildschut: 2011). Standardised interviews include interviewer administered questionnaires. Non-standardised interviews include two types which are one-to-one and one-to-many. Under the one-to-one category falls face-to-face interviews, telephonic interviews as well as "internet and intranet mediated" interviews. The one-to-many category includes group interviews which can be focus groups and also "internet and intranet mediated" interviews which may also include focus group interviews. Group interviews have several types, the table 1 below illustrates that;

Table 1:

\begin{tabular}{|c|c|c|c|c|}
\hline Type & setting & interviewer Role & Question format & purpose \\
\hline Focus group & Formal-preset & Directive & Structured & Exploratory \\
\hline Brainstorming & Formal/informal & Non directive & Very structured & Exploratory \\
\hline Nomial/delph & Formal & Directive & Structured & Exploratory \\
\hline Field, natural & Informal & Non directive & Very structured & Exploratory phenomenology \\
\hline Field, formal & Preset in field & Directive & Semi-structured & Phenomenology \\
\hline
\end{tabular}

Source: Denzin \& Lincoln: 2006

Moreover, Lincoln \& Guba (1985); Kvale (1986); Richardson, Dohrenwend \& Klein (1965); Rubin \& Rubin (1995); Spradley (1979); Ellen (1984); Bertaux (1981); Brigs (1986); Mishler (1986) in Seidman (1998) provide a comprehensive description of interviewing approaches. It is important to note that interviewing techniques are determined by the theoretical underpinning of one's approach to interviewing (Seidman, 1998) siting Kvale (1996).

Qualitative interviewing is also comprehensively discussed by Kvale (1996); Seidman (1991); Weiss (1994). Other styles of interviews include focus group interviews Greenbaum (1993); Kueger \& Kasey (2000); Morgan \& Krueger (1998), "Long interview" (MeCracken: 1998), oral history interviews (Dunway \& Baum: 1996) and ethnographic interview (Spradley: 1997).

Kvale in Babbie and Mouton (2011) metaphorically defines an interviewer as a "miner" or a traveller. The first metaphor implies that the interviewee has information which must be "dug out" by the interviewer while the interviewer as the "traveller" model implies that the interviewer "wanders through the landscape and enters into conversations with the people (and) explores the many domains of the country, as unknown territory or with maps, roaming freely around the territory" (ibid). Interviewers must be people who are critical, knowledgeable, sensitive, and open and while they give structure to the interview, they must also have a good memory and interpret statements made by interviewers correctly without imposing meanings on what the interviewers will be saying (Wildschut: 2011).

Babbie and Mouton succinctly observe that it is very important to ask ourselves where the interview data is going to come from, before we even carry out interviews. Spradley in Babbie and Mouton (2011) identifies three criteria which are crucial for the selection of respondents and seven stages in a complete process of interviewing. The three criteria are "enculturation", "current involvement" and "adequate time".

Patton \& Mishler in Seidman (1998) emphasise the utility of life contexts in interviewing and warn that interviewers who only have a once off meeting with interviewees will be treading on "contextual ice" (Seidman: 1998). Three interview series are meant to capture the context of the interviewee by focusing on life histories; details of experiences and reflection on the meaning of those experiences with each sere focusing on each of these three issues for every respondent.

Babbie \& Mouton (2011) advise that there is a crucial first step which must be taken in interviewing which entails formulation of "broad, overall questions to be answered". These include "Why is the study being done? What do we hope to be able to say or prove? Are we primarily describing what has taken place in a program? Do we want to compare what has happened with some established or implied standard or (lastly do we want to determine if a program has made a difference, a cause and effect type question") (ibid). These key questions are very important and serve as pre-requisites for the collection of valid interview data. 


\section{Strengths and Weaknesses of Interviewing}

(Seidman: 1998) asks a very important question which unearths one of the weaknesses of interviewing; "whose meaning is it that an interview brings forth and that a researcher reports?" Sapsford \& Jupp (2006) also opine that "the effect of context on responses is sometimes a critical one", they go on to argue that the context affects response rates. This, to some extent, implies that both the interviewer and the interviewing situation have an impact on the reconstruction of the experiences by the respondents. Roulston, deMarris \& Lewise (2003: 643) opine that there are challenges which confront inexperienced interviewers in interviewing such as "unexpected participant behaviour, dealing with the consequences of the interviewer's own action and subjectivities, constructing and delivering questions and handling sensitive topics". Therefore, given the foregoing succinct observations, the interviewer must work diligently to ensure the validity and reliability of the interview data otherwise, interviewers themselves, can turn to be weaknesses due to their own bias, subjectivities and lack of interviewing skills.

It is important to note that interviewers themselves become part of the "interviewing picture" by asking questions and responding to the respondent and sometimes even sharing their experiences with interviewees; working with the interview data, selecting from it, interpreting and describing and analysing it regardless of their discipline and dedication in keeping the interview data as the product of the respondent (Ferrarotti: 1981; Kvale: 1996 \& Mishler: 1986 in Seidman: 1998).

Weaknesses of interviewing have been both discussed and critiqued from different theoretical perspectives which are "postmodern, feminist, sociolinguistic" (Briggs: 1992; Graham: 1983; Oakely: 1981; Sheurich: 1995), "conversation analytic", "ethnomethodological perspectives" and even data analysis (Rapley: 2001; Rapley \& Anaki; Baker: 1997, 2002; Roulston: 2001; Roulston, Baker \& Liljestron: 2001 in Roulston, deMarris \& Lewise (2003). A number of strengths and weaknesses can be identified for several approaches to interviewing as follows;

\subsection{In-depth Interviews}

In-depth interviews are typical qualitative research interviews (Lincold \& Guba: 1985; Taylor \& Bogdan: 1984). The use of in-depth interviews is predicted on the assumption that social reality is subjective and therefore requires the researcher to engage with the units of analysis (individuals) and one way of doing that is through carrying out in-depth interviews. Indepth interviews are crucial for data collection on personal experiences and perspectives.

In-depth interviews for example, have several merits. They normally provide rich and detailed data with "new insights". Because of their greater flexibility, they allow in-depth exploration; they also minimize errors of misinterpretation and misrepresentation due to the possibility of repeating, rephrasing and emphasizing. In-depth interviews are also ideal for complex and sometimes emotionally laden issues while probing for sentiments underlying expressed opinion is also made easier with in-depth interviews.

Weaknesses of in-depth interviews are that their flexibility may imply that they are not reliable and they also need highly skilled interviewers apart from the fact that they consume both time and financial resources. Their subjectivity may mean that respondents may "say" what the interviewer wants to hear, therefore, the validity and reliability of the interview data may be questionable.

While closed-ended questions in in-depth interviews are popular for their uniformity of responses which can be easily processed their major drawback lies in the structuring of the responses since the researcher may overlook important questions. However, exhaustive response categories which are mutually exclusive may be employed to counter the above-mentioned weakness.

Unstructured interviews on the other hand can ensure that respondents do not live out important issues which they have to mention although there is a danger in that respondents may convey irrelevant information to the researcher while the chances of researcher bias and misunderstanding cannot be ruled out.

\subsection{Semi-structured interviews}

In semi-structured interviews "the researcher has a list of questions or fairly specific topics to be covered, often referred to as an interview guide, but the interviewee has a great deal of lee way in how to reply" (Bryman: 2004). Their strength therefore lie in that they are flexible. Robson (2002) opines "that face-to-face interviews offer possibility of modifying responses and investigating underlying responses. 


\subsection{Structured interviews}

Structured interviews also have their own strengths and weaknesses. Their strength is that they provide reliable data for quantitative methodologies while many respondents may be engaged efficiently. Structured interviews are very useful for formative assessments and they allow standardization and replication while they are quick and easy to create and code and interpret and many respondents can be engaged easily.

However, their weaknesses lie in their inflexibility which leaves little room for "unanticipated discoveries" while they also require substantial pre-planning and it is the quality of the questions that will determine the quality of the data (Brawell, Hammond \& Fife-schaw: 1997 in Oatey: undated).

Moreover, the scope of the interviewee is most likely to be limited in both detail and depth while the presence of the interviewer may lead to bias in responses since the respondent may be tempted to impress the interviewer. Another common weakness is that the list of questions are suggestive and imply that the interviewer has effectively made a decision on what they consider important or not, even before the interview is carried out.

\subsection{Focus group interviews}

Babbie \& Mouton (2011) write that there are two ways of using focus group interviews within the paradigm of qualitative research. The first one is the "get-ten-for-the-price-of-one" which involves between eight and twelve respondents set up in a circle with the interviewer going around the circle to get responses from all the individuals within the circle. While this approach saves both money and time it is criticised since it compromises quality of the data because "valuable data" on both group and individual levels is lost.

The second approach to focus group interviewing is using the group to get information you would not otherwise get from individuals when the group creates meanings collectively rather than as individuals. The snow-boll effect of focus group discussions is advantageous in that it stimulates contribution of interesting issues and topics which could be useful to the interviewer.

Focus groups interviews like other approaches have their weaknesses and strengths. Morgan in Babbie \& Mouton (2011) observes that "the main advantage of focus groups in comparison to participant observation is the opportunity to observe a large amount of interaction on a topic in a limited period of time based on the researcher's ability to assemble and direct." Moreover, focus groups provide an interesting environment for participants to engage each other in the articulation of important and interesting issues to them in the course of the discussion (Goulding: 1997).

However, focus groups also reveal a disadvantage in that this direction given by the interviewer implies that "focus groups are in some sense unnatural social settings" (ibid). Focus groups also require great attention from the interviewer's role and they provide less depth and detail about the opinions and experiences of any given participant. Wimmer and Dominic (1997) opine that

Some researchers claim that focus groups are not a good research methodology because of the potential influence of one or more respondent on the remaining members of the group. These critics say that a dominant respondent may negatively affect the outcome of a group and that group pressure may influence the comments made by individuals.

\subsection{Telephonic interviews}

Telephone interviews have also been highlighted as another style of interviewing and they also have their own strengths and weaknesses. While it is a convenient way of interviewing which does not have the hussles of travelling to meet interviewers, its main disadvantage is that it may be expensive. However, respondents in telephone interviews have "facial anonymity" which may make them contribute in ways they would not, in a face to face interview, thereby, raising some interesting unanticipated issues.

\subsection{Face-to-face Interviews}

Face to face interviews have their strengths and weaknesses. Unlike the telephonic interview the face-to-face interview provides the interviewer with an opportunity to observe non-verbal communication issues and listen at the same time. They may be a fast way of collecting data and they also enjoy a high response rate unlike other types. The interviewer has an opportunity to probe and seek clarification while the respondent may equally seek for clarification or explanation of grey areas. 
Moreover, Robson (2002) argues that "face to face interviews offer possibility of modifying one's enquiry, following up interesting responses and investigating underlying responses". Non-verbal cues observed in face to face interviews also illustrate meanings. However, face-to-face interviews may be expensive and they also need trained interviewers while the time spent on travelling and making appointment constitutes another drawback. Lack of standardisation resulting from these interviews also raises reliability concerns.

\section{Conclusion}

Interviewing is one of the most common data collection methods that are employed in qualitative research. Although interviews have various forms and styles, it is important to note that there is no one interview style that fits every occasion or all respondents. The interviewer must work diligently to ensure the validity and reliability of the interview data otherwise, interviewers themselves, can turn out to be weaknesses due to their own bias, subjectivities and lack of interviewing skills.

It is also important to note that interviewers themselves become part of the "interviewing picture" by asking questions and responding to the respondent and sometimes even sharing their experiences with interviewees; working with the interview data, selecting from it, interpreting and describing and analysing it regardless of their discipline and dedication in keeping the interview data as the product of the respondent. Weaknesses of interviewing have been both discussed and critiqued from different theoretical perspectives which are "postmodern, feminist, sociolinguistic" (Briggs: 1992; Graham: 1983; Oakely: 1981; Sheurich: 1995), "conversation analytic", "ethnomethodological perspectives" and even data analysis (Rapley: 2001; Rapley \& Anaki; Baker: 1997, 2002; Roulston: 2001; Roulston, Baker \& Liljestron: 2001 in Roulston, deMarris \& Lewise (2003).

\section{References}

Babbie, E \& Mouton, J. 2011. The Practice of Social Research, Oxford University Press: Cape Town.

Berg, B. L. 1989. Qualitative Research Methods for the Social Sciences. Nadham Hiegths: MS: Allyn \& Bacon.

Bryman, A. 2004. Social Research Methods, Oxford University Press: New York.

Byrne, M (undated). Interviewing as a data collection method. Accessed online from http://findarticles.com/p/articles/

Dexter, L.A. 1970. Elite and Specialised Interviewing. Evanston: North-western University Press.

Denzin, N. K. \& Lincoln, S. Y. 2006. Handbook on Qualitative Research, Sage: Thousand Oaks.

Goulding, A. 1997. Joking, being aggressive and shutting people up: the use of focus groups in LIS research, Education for Information 15, 4, pp. 331-341.

Lincoln, Y. \& Guba, E. 1985. Naturalistic Enquiry. New York: Sage.

Mishler. T. 1986. Research Interviewing: Context and Narrative. Cambridge. MA: Harvard University Press.

Oatey, A. undated. The strength and limitation of interviews as interviewing techniques for studying television viewers accessed online from http://www.aber.ac.uk/media/Students

Robinson, C. 2002. Real World Research, Blackwell: Victoria.

Roulston, K. deMarris, K. \& Lewise, J. 2003 Learning to interview in Social Sciences, accessed online from https://entwicklungspolitik.uni-hohenheim.de/uploads.

Sapsford, R. \& Jupp, V. Data Collection and Analysis, Sage: London.

Seidman, I. 1998. Interviewing as Qualitative Research, A Guide for Researchers in Education and the Social Sciences, accessed from online from web studies, University of Stellenbosch.

Taylor, S.J. \& Bogdan, R. 1984. Introduction to Qualitative Research Methods. Newyork: John Wileys \& Sons.

Wildschut, I. 2011. Introduction to Interviewing, Module Notes, University of Stellenbosch. 